\title{
Hypervascularized bronchial arteries as a risk factor for intraoperative bleeding and prolonged surgery
}

\author{
Hiromitsu Takizawa ${ }^{1}$, Naoki Miyamoto ${ }^{1}$, Shinichi Sakamoto ${ }^{1}$, Mika Takashima ${ }^{1}$, Daisuke Matsumoto ${ }^{1}$, \\ Naoya Kawakita ${ }^{1}$, Hiroaki Toba ${ }^{1}$, Yukikiyo Kawakami ${ }^{1}$, Mitsuteru Yoshida ${ }^{1}$, Kazuya Kondo ${ }^{2}$, Akira Tangoku ${ }^{1}$ \\ ${ }^{1}$ Department of Thoracic, Endocrine Surgery and Oncology, Tokushima University Graduate School of Biomedical Sciences, Kuramotocho, \\ Tokushima, Japan; ${ }^{2}$ Department of Oncological Medical Services, Tokushima University Graduate School of Biomedical Sciences, Kuramotocho, \\ Tokushima, Japan \\ Contributions: (I) Conception and design: H Takizawa; (II) Administrative support: H Takizawa; (III) Provision of study materials or patients: \\ H Takizawa, H Toba, M Yoshida, Y Kawakami, K Kondo; (IV) Collection and assembly of data: N Miyamoto, S Sakamoto, M Takashima, D \\ Matsumoto, N Kawakita; (V) Data analysis and interpretation: H Takizawa, N Kawakita; (VI) Manuscript writing: All authors; (VII) Final approval of \\ manuscript: All authors. \\ Correspondence to: Hiromitsu Takizawa. Department of Thoracic, Endocrine Surgery and Oncology, Tokushima University Graduate School of \\ Biomedical Sciences, 3-18-15, Kuramotocho, Tokushima 770-8503, Japan. Email: takizawa@tokushima-u.ac.jp.
}

\begin{abstract}
Background: The present study investigated whether highly vascularized bronchial arteries affect the intraoperative blood loss and the operative time of video-assisted thoracic surgery (VATS) lobectomy for patients with non-small cell lung cancer.

Methods: We retrospectively collected data on consecutive pathological stage I to IIIA non-small cell lung cancer patients who underwent VATS lobectomy with systematic lymph node dissection between January 2017 and December 2019. Patients were divided into the following two groups according to bronchial artery diameters on preoperative enhanced contrast computed tomography (CT) findings: $\leq 2$ and $>2 \mathrm{~mm}$ groups.

Results: Among the 175 patients enrolled, risk factors for intraoperative blood loss $>50 \mathrm{~mL}$ were being male $(\mathrm{P}=0.005)$, a history of smoking $(\mathrm{P}=0.01)$, percent forced expiratory volume in $1 \mathrm{~s}(\mathrm{FEV} 1.0 \%)<70 \%$ $(\mathrm{P}=0.012)$, squamous cell carcinoma $(\mathrm{P}=0.049)$, and a bronchial artery diameter $>2.0 \mathrm{~mm}(\mathrm{P}<0.001)$ in the unadjusted analysis, and a bronchial artery diameter $>2.0 \mathrm{~mm}(\mathrm{P}<0.001)$ in the multivariable analysis. Risk factors for an operative time $>200$ min were being male $(\mathrm{P}<0.001)$, a history of smoking $(\mathrm{P}=0.007), \mathrm{FEV} 1.0 \%$ $<70 \%(\mathrm{P}=0.011)$, squamous cell carcinoma $(\mathrm{P}=0.046)$, a bronchial artery diameter $>2.0 \mathrm{~mm}(\mathrm{P}<0.001)$, and experience of surgeon $<10$ years $(\mathrm{P}=0.011)$ in the unadjusted analysis, and being male $(\mathrm{P}=0.047)$, a bronchial artery diameter $>2.0 \mathrm{~mm}(\mathrm{P}=0.024)$, and experience of surgeon $<10$ years $(\mathrm{P}=0.047)$ in the multivariable analysis.

Conclusions: Bronchial artery diameter was the most important risk factor of intraoperative bleeding and prolonged operative time during VATS lobectomy.
\end{abstract}

Keywords: Lung cancer; bronchial artery; video-assisted thoracic surgery (VATS); intraoperative blood loss; operative time

Submitted Apr 08, 2021. Accepted for publication Jun 19, 2021.

doi: $10.21037 /$ jtd-21-616

View this article at: https://dx.doi.org/10.21037/jtd-21-616

\section{Introduction}

The standard surgical procedure for primary lung cancer is lobectomy with systematic lymph node dissection, and video-assisted thoracic surgery (VATS) has recently become more mainstream (1). It has been nearly 30 years since VATS lobectomy was initially reported (2). In Japan, approximately $70 \%$ of surgeries performed for primary lung cancer involve VATS, and the 30 -day postoperative mortality rate is $0.3 \%$, 
which is very safe (3). In recent year, the feasibility of VATS lobectomy for stage II (cN1) non-small cell lung cancer (NSCLC) has also been demonstrated (4). Although the surgical procedure for VATS lobectomy is established and widely performed, increases in both intraoperative bleeding and the operative time are sometimes encountered.

The sequence of vessel interruption during lobectomy remains controversial (4-6). One of the merits of firstly sealing the pulmonary veins is that it may prevent the outflow of tumor cells into the circulation and distant metastasis (5). However, it may also cause congestion of the lobe to be resected, resulting in increases in both intraoperative blood loss and the operative time (6). However, previous studies reported no significant differences in intraoperative blood loss and operative times between cases in which either the pulmonary veins or arteries were initially sealed $(5,7)$. One of the reasons for this finding is that not only pulmonary arteries, but also bronchial arteries may cause congestion of the lobe to be resected after pulmonary vein sealing.

Bronchial arteries generally originate from the proximal descending thoracic aorta $(8,9)$. Normal bronchial arteries are small, measuring less than $2 \mathrm{~mm}$ at their origin, receive only approximately $1 \%$ of the total cardiac output, and help maintain airway and lung function $(10,11)$. They provide a systemic blood supply to the trachea, bronchi, bronchial branches, esophagus, visceral pleura, vasa vasorum of the thoracic aorta, and pulmonary arteries as well as to the nerves, pulmonary veins, and lymph nodes in the thorax (12). Bronchial arteries carry oxygenated blood to the lungs at a pressure that is six-fold higher than that in the pulmonary arteries. Therefore, highly vascularized bronchial arteries may contribute to bleeding during lung cancer surgery.

The present study investigated whether highly vascularized bronchial arteries affect intraoperative blood loss in and the operative time of VATS lobectomy with systematic lymph node dissection, and attempted to identify the factors that correlate with hypervascularized bronchial arteries.

We present the following article in accordance with the STROBE reporting checklist (available at https://dx.doi. org/10.21037/jtd-21-616).

\section{Methods}

\section{Patients}

We retrospectively collected data on consecutive NSCLC patients who underwent resection at Tokushima University Hospital between January 2017 and December 2019. Patients who met the following criteria were included: pathologically confirmed stage I to IIIA NSCLC; no preoperative treatment; VATS lobectomy with systematic lymph node dissection; and complete curative resection. Patients with the following factors were excluded: no preoperative contrastenhanced computed tomography (CT) or no arterial phase during contrast-enhanced CT, previous surgery on the ipsilateral thoracic cavity, the resection of surrounding tissue, simultaneous surgical procedures, and conversion from VATS to open surgery. The presence of interstitial lung disease was defined when CT findings showed ground-glass opacities, irregular linear opacities, honeycombing, or consolidation in the lung field. Clinicopathological, operative, and postoperative data were collected from a retrospective review of medical records. The Ethics Committee of Tokushima University Hospital approved the study protocol in March 2020 (No. 3672). The need for written informed consent was waived because of the retrospective study design. The study was conducted in accordance with the Declaration of Helsinki (as revised in 2013).

\section{CT protocol}

Contrast-enhanced CT images were acquired using a 16-slice multidetector CT (MDCT) scanner (Aquilion16; Toshiba Medical Systems Corporation, Tochigi, Japan; SOMATOM Sensation 16; Siemens, Erlangen, Germany) or a 320-slice MDCT scanner (Aquilion One; Toshiba Medical Systems Corporation, Tochigi, Japan). One hundred milliliters of iohexol (Omnipaque, $300 \mathrm{mg}$ of iodine per milliliter; DaiichiSankyo Pharmaceutical, Tokyo, Japan) was intravenously injected at a rate of $3.0 \mathrm{~mL} / \mathrm{s}$, followed by an injection of $40 \mathrm{~mL}$ of saline solution. Arterial and equilibrium phase scanning was performed. In the arterial phase, scanning was initiated using a bolus-tracking method. The region of interest was set at the descending aorta, and the threshold for the CT value was $100 \mathrm{HU}$. When the CT value surpassed the threshold, scanning was automatically started and followed by equilibrium phase scanning $100 \mathrm{~s}$ after completion of the arterial phase. CT scanning was performed using the following parameters: gantry rotation speed of $0.5 \mathrm{~s}$ per rotation, 1-mm collimation for the 16-slice MDCT scanner and $0.5-\mathrm{mm}$ collimation for the 320-slice MDCT scanner, $15 \mathrm{~mm} / \mathrm{s}$ table increment with a helical pitch of 15 , tube voltage of $120 \mathrm{kV}$, and tube current of $300 \mathrm{~mA}$.

\section{Measurement of the bronchial artery diameter}

The identification and measurement of bronchial arteries were 

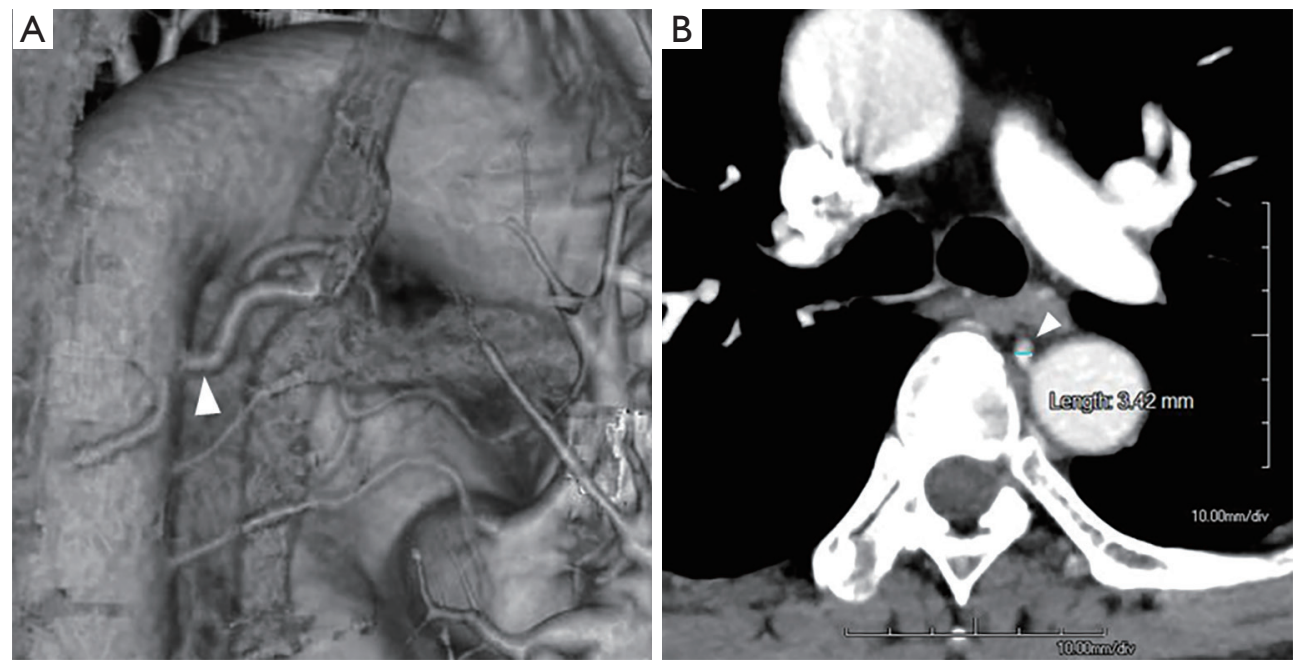

Figure 1 CT images of bronchial artery. (A) A three-dimensional CT image rendered using 1-mm-thick multi-detector CT images [arrowheads: an origin of the right bronchial artery (common intercostal-bronchial artery trunk)]; (B) a contrast-enhanced CT image in the arterial phase [arrowheads: an origin of the right bronchial artery (the common intercostal-bronchial artery trunk)]. CT, computed tomography.

performed using commercially available software (Aquarius NET Viewer Version 4.4.11.265; TeraRecon Inc., San Mateo, CA, USA) (Figure 1A). In the arterial phase of contrastenhanced CT, bronchial arteries leading to the lobe to be resected were identified. Artery diameters were measured at the point arising from the thoracic aorta (Figure 1B). On the right side, the artery was sometimes a common intercostalbronchial artery trunk. Patients were divided into the following two groups based on bronchial artery diameters: $\leq 2$ and $>2 \mathrm{~mm}$ groups, since the diameter of the bronchial artery is usually $2 \mathrm{~mm}$ or less (10).

\section{Surgical procedures}

Patients underwent VATS lobectomy with systematic hilar and mediastinal lymph node dissection. A $1.5-\mathrm{cm}$ camera port was created in the 8 th intercostal space at the midaxillary line, a 4-cm working window for the surgeon in the 4th intercostal space at the anterior axillary line, and a $3-\mathrm{cm}$ working window for the assistant in the 6th or 7th intercostal space at the posterior axillary line. Endostaplers were used to seal the pulmonary artery, pulmonary vein, and bronchus and divide the interlobar fissure, and small branches of the vessels were sealed with LigaSure (Medtronic, Minneapolis, Minn). The sequence of procedures was decided by each surgeon. Mediastinal lymph node dissection was achieved after lobectomy in all cases. The TNM classification was assessed according to the Union for International Cancer Control staging system, version 8 .

\section{Statistical analysis}

GraphPad prism 5 software was used to analyze the linear correlations between intraoperative blood loss, operative time, and bronchial artery diameter. The Mann-Whitney $\mathrm{U}$ test was used to calculate the impact of bronchial artery dilation on intraoperative blood loss and the operative time. The chi-squared test was performed to compare categorical variables. Pearson's chi-squared test or Fisher's exact test was applied to verify relationships between the groups. A logistic regression analysis was used to identify prognostic risk factors. Potentially predictive variables were identified using a significance level of $\mathrm{P}<0.10$ by a univariate analysis and were then subjected to a logistic regression multivariable analysis. All statistical analyses were performed using IBM SPSS Statistics (version 22; IBM Corp., Armonk, NY, USA). $\mathrm{P}<0.05$ was considered to be significant.

\section{Results}

\section{Clinicopathological characteristics of NSCLC patients who underwent VATS lobectomy}

A total of 215 patients underwent curative VATS lobectomy with systematic lymph node dissection for the treatment of 


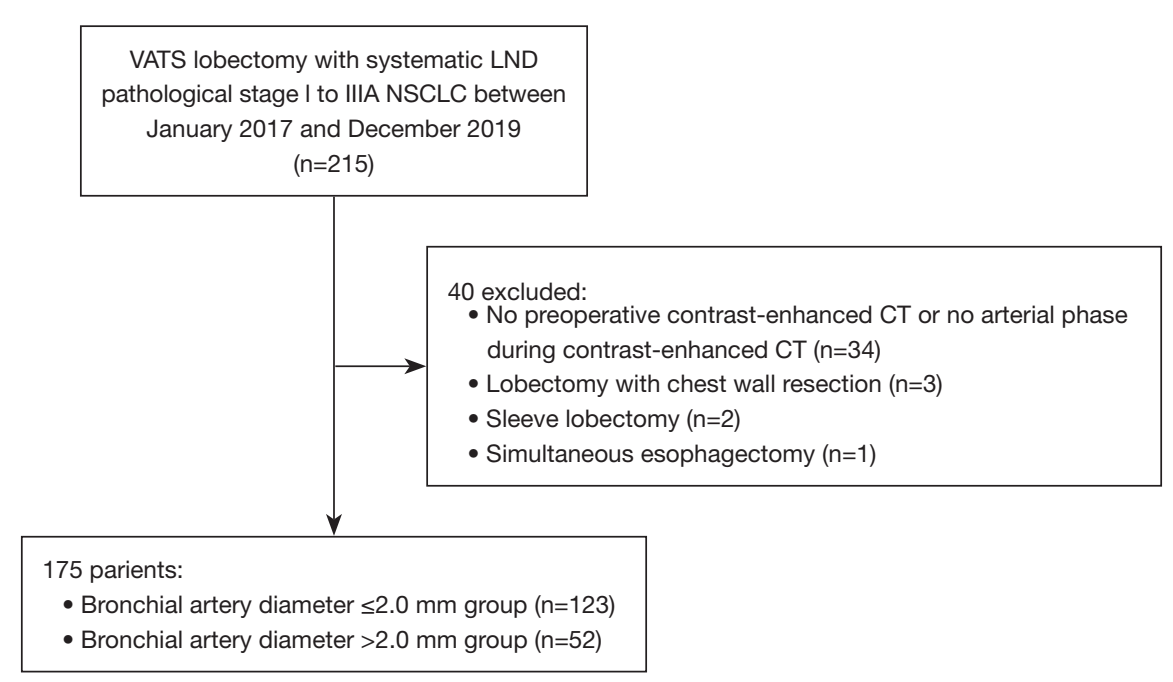

Figure 2 Flow chart for the study population. VATS, video-assisted thoracic surgery; LND, lymph node dissection; NSCLC, non-small cell lung cancer; CT, computed tomography.

pathological stage I to IIIA NSCLC without preoperative treatment during the study period. Among them, 40 patients were excluded because of no preoperative contrast-enhanced CT or no arterial phase during contrast-enhanced CT (n=34), lobectomy with chest wall resection $(\mathrm{n}=3)$, sleeve lobectomy $(\mathrm{n}=2)$, and simultaneous esophagectomy $(\mathrm{n}=1)$. There was no conversion case from VATS to open surgery. Therefore, 175 patients were included in the present study (Figure 2); 109 males $(62.3 \%)$ with a median age of 72 years [interquartile range (IQR), 66-78 years] and 106 with a history of smoking (60.6\%). The median tumor size was $19 \mathrm{~mm}$ (IQR, 12-29 mm). Tumor locations were as follows: the right upper lobe in 66 patients (37.7\%), the right middle lobe in $12(6.9 \%)$, the right lower lobe in $34(19.4 \%)$, the left upper lobe in 27 (15.4\%), and the left lower lobe in $36(20.6 \%)$. Interstitial lung disease was identified in 51 patients (29.1\%). The histological type was squamous cell carcinoma in 33 patients (18.9\%), adenocarcinoma in $128(73.1 \%)$, and other types in 14 (8.0\%). The pathological stages of 0/IA/ IB/IIA/IIB/IIIA were $4(2.3 \%) / 127(72.6 \%) / 16(9.1 \%) / 6$ $(3.4 \%) / 17(9.7 \%) / 5(2.9 \%)$. The median diameter of bronchial arteries was $1.8 \mathrm{~mm}$ (IQR, 1.6-2.2 mm).

\section{Surgeons and outcomes of surgery}

During the study period, 17 surgeons participated as the chief surgeon. Their years of experience as surgeons were 2 , $3,3,4,6,7,9,10,10,12,12,12,15,20,22$, 22, and 22 years. In surgery performed by a surgeon with less than 15 years of experience, a senior doctor (experience of 20, 22, 22, 22, and 34 years) instructed the surgery as an assistant. Median intraoperative blood loss was $27 \mathrm{~mL}$ (IQR, 3-100 mL) and the median operative time was $197 \mathrm{~min}$ (IQR, 156-240 min). No patient required a blood transfusion due to intraoperative bleeding, reoperation and interventional radiology due to postoperative bleeding. No patient died during the perioperative period.

\section{Correlations between intraoperative blood loss, operative time and bronchial artery diameter}

Figure $3 A$ shows correlation between intraoperative blood loss and bronchial artery diameter $\left(\mathrm{r}^{2}=0.155, \mathrm{P}<0.0001\right)$, and Figure $3 B$ shows correlation between operative time and bronchial artery diameter $\left(\mathrm{r}^{2}=0.105, \mathrm{P}<0.0001\right)$. There were poor correlations between intraoperative blood loss, operative time and bronchial artery diameter.

\section{Risk factors for intraoperative bleeding and prolongation of the operative time}

Table 1 shows intraoperative blood loss and operative times in the groups with bronchial artery diameters $\leq 2.0$ and $>2.0 \mathrm{~mm}$. Risk factors for intraoperative blood loss $>50 \mathrm{~mL}$ were being male $(\mathrm{P}=0.005)$, a history of smoking $(\mathrm{P}=0.01)$, percent forced expiratory volume in $1 \mathrm{~s}$ (FEV1.0\%) $<70 \%(\mathrm{P}=0.012)$, squamous cell carcinoma $(\mathrm{P}=0.049)$, and a bronchial artery diameter $>2.0 \mathrm{~mm}(\mathrm{P}<0.001)$ in 

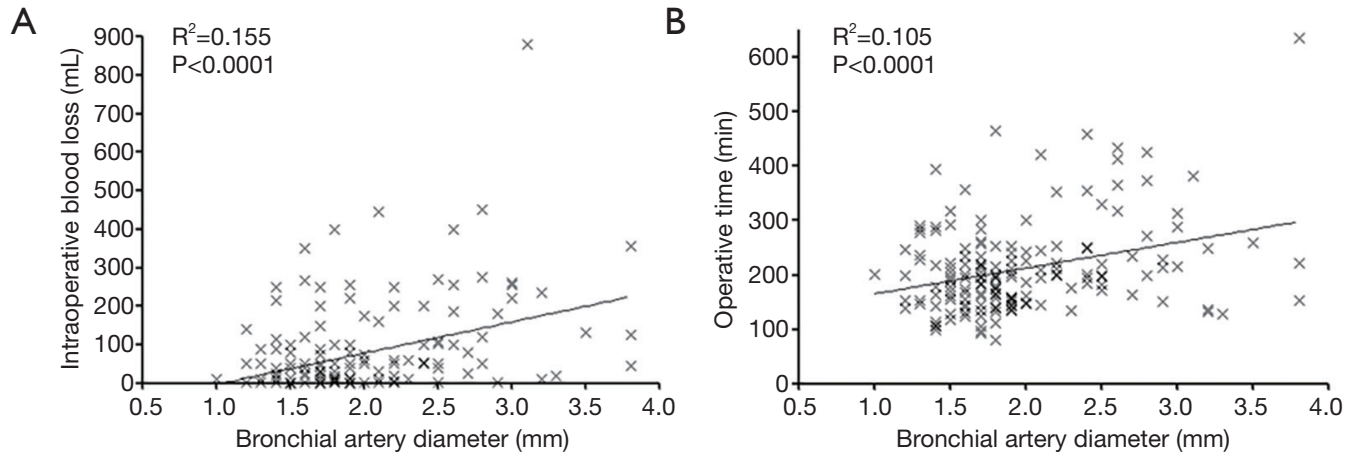

Figure 3 Correlations between intraoperative blood loss, operative time and bronchial artery. (A) Correlations between intraoperative blood loss and bronchial artery diameter; (B) correlations between operative time and bronchial artery diameter.

Table 1 Clinicopathological characteristics

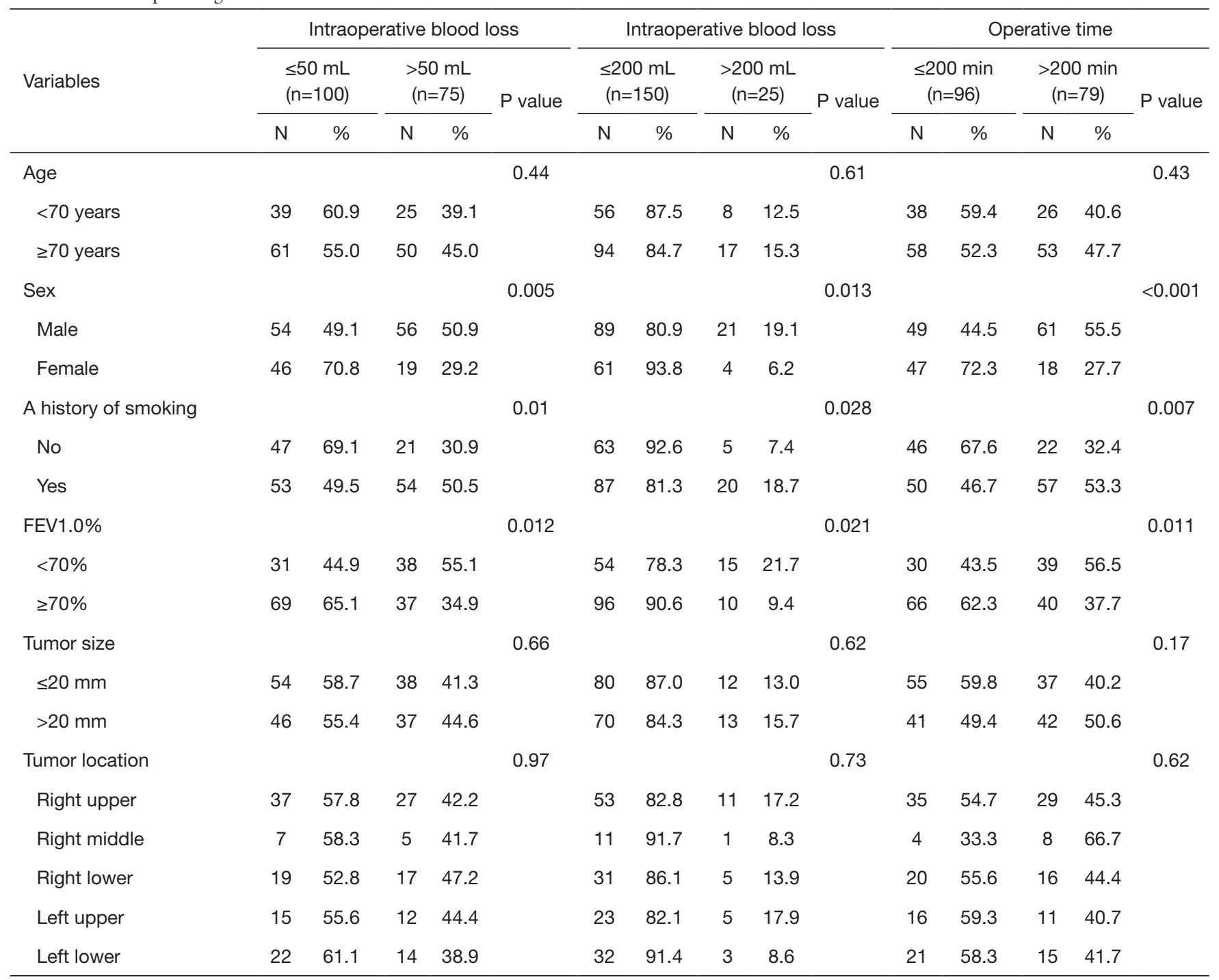

Table 1 (continued) 
Table 1 (continued)

\begin{tabular}{|c|c|c|c|c|c|c|c|c|c|c|c|c|c|c|c|}
\hline \multirow[b]{2}{*}{ Variables } & \multicolumn{5}{|c|}{ Intraoperative blood loss } & \multicolumn{5}{|c|}{ Intraoperative blood loss } & \multicolumn{5}{|c|}{ Operative time } \\
\hline & \multicolumn{2}{|c|}{$\begin{array}{l}\leq 50 \mathrm{~mL} \\
(\mathrm{n}=100)\end{array}$} & \multicolumn{2}{|c|}{$\begin{array}{c}>50 \mathrm{~mL} \\
(\mathrm{n}=75)\end{array}$} & $P$ value & \multicolumn{2}{|c|}{$\begin{array}{c}\leq 200 \mathrm{~mL} \\
(\mathrm{n}=150)\end{array}$} & \multicolumn{2}{|c|}{$\begin{array}{c}>200 \mathrm{~mL} \\
\quad(\mathrm{n}=25)\end{array}$} & $P$ value & \multicolumn{2}{|c|}{$\begin{array}{c}\leq 200 \min \\
\quad(n=96)\end{array}$} & \multicolumn{2}{|c|}{$\begin{array}{c}>200 \text { min } \\
(n=79)\end{array}$} & $P$ value \\
\hline Interstitial lung disease & & & & & 0.18 & & & & & 0.066 & & & & & 0.24 \\
\hline Histological type & & & & & 0.049 & & & & & 0.057 & & & & & 0.046 \\
\hline Squamous cell carcinoma & 13 & 39.4 & 20 & 60.6 & & 24 & 72.7 & 9 & 27.3 & & 12 & 36.4 & 21 & 63.6 & \\
\hline Adenocarcinoma & 80 & 62.5 & 48 & 37.5 & & 114 & 89.1 & 14 & 10.9 & & 77 & 60.2 & 51 & 39.8 & \\
\hline I & 85 & 59.4 & 58 & 40.6 & & 123 & 86.0 & 20 & 14.0 & & 80 & 55.9 & 63 & 44.1 & \\
\hline II & 10 & 43.5 & 13 & 56.5 & & 20 & 87.0 & 3 & 13.0 & & 12 & 52.2 & 11 & 47.8 & \\
\hline III & 2 & 40.0 & 3 & 60.0 & & 4 & 80.0 & 1 & 20.0 & & 2 & 40.0 & 3 & 60.0 & \\
\hline Bronchial artery diameter & & & & & $<0.001$ & & & & & $<0.001$ & & & & & $<0.001$ \\
\hline$\leq 2.0 \mathrm{~mm}$ & 84 & 68.3 & 39 & 31.7 & & 114 & 92.7 & 9 & 7.3 & & 78 & 63.4 & 45 & 36.6 & \\
\hline$>2.0 \mathrm{~mm}$ & 16 & 30.8 & 36 & 69.2 & & 36 & 69.2 & 16 & 30.8 & & 18 & 34.6 & 34 & 65.4 & \\
\hline Experience of surgeon & & & & & 0.28 & & & & & 0.344 & & & & & 0.011 \\
\hline
\end{tabular}

the unadjusted analysis (Table 1), and a bronchial artery diameter $>2.0 \mathrm{~mm}(\mathrm{P}<0.001)$ in the multivariable analysis (Table 2). Unadjusted analysis of intraoperative blood loss was also performed between $\leq 200$ and $>200 \mathrm{~mL}$ groups; however, the results were similar (Table 1). Risk factors for an operative time $>200$ min were being male $(\mathrm{P}<0.001)$, a history of smoking $(\mathrm{P}=0.007), \mathrm{FEV} 1.0 \%<70 \%(\mathrm{P}=0.011)$, squamous cell carcinoma $(\mathrm{P}=0.046)$, a bronchial artery diameter $>2.0 \mathrm{~mm}(\mathrm{P}<0.001)$, and experience of surgeon $<10$ years $(\mathrm{P}=0.011)$ in the unadjusted analysis (Table 1$)$, and being male $(\mathrm{P}=0.047)$, a bronchial artery diameter $>2.0 \mathrm{~mm}$ $(\mathrm{P}=0.024)$, and experience of surgeon $<10$ years $(\mathrm{P}=0.047)$ in the multivariable analysis (Table 2).

\section{Factors correlating with bronchial artery dilation}

The bronchial artery diameter $>2.0 \mathrm{~mm}$ group included more males $(\mathrm{P}<0.001)$, a history of smoking $(\mathrm{P}<0.001)$, the presence of interstitial lung disease $(\mathrm{P}<0.001)$, squamous cell carcinoma $(\mathrm{P}=0.049)$, and an advanced pathological stage (Table 3).

\section{Operative and postoperative results correlating with bronchial artery dilation}

Table 4 shows operative and postoperative results in the groups with bronchial artery diameters $\leq 2.0$ and $>2.0 \mathrm{~mm}$. In the bronchial artery dilation group, intraoperative blood loss was significantly greater (median, $100 v s .10 \mathrm{~mL}$; IQR, 29-205 vs. 3-50 mL; $\mathrm{P}<0.0001)$, the operative time was significantly longer (median, 220 vs. $181 \mathrm{~min}$; IQR, 196-314 vs. $151-219 \mathrm{~min} ; \mathrm{P}<0.0001)$, postoperative complications were significantly more frequent $(38.5 \%$ vs. $9.8 \% ; \mathrm{P}<0.0001)$, and postoperative hospital stay significantly longer (median, 
Table 2 Multivariate analysis of relations with intraoperative blood loss and operative time

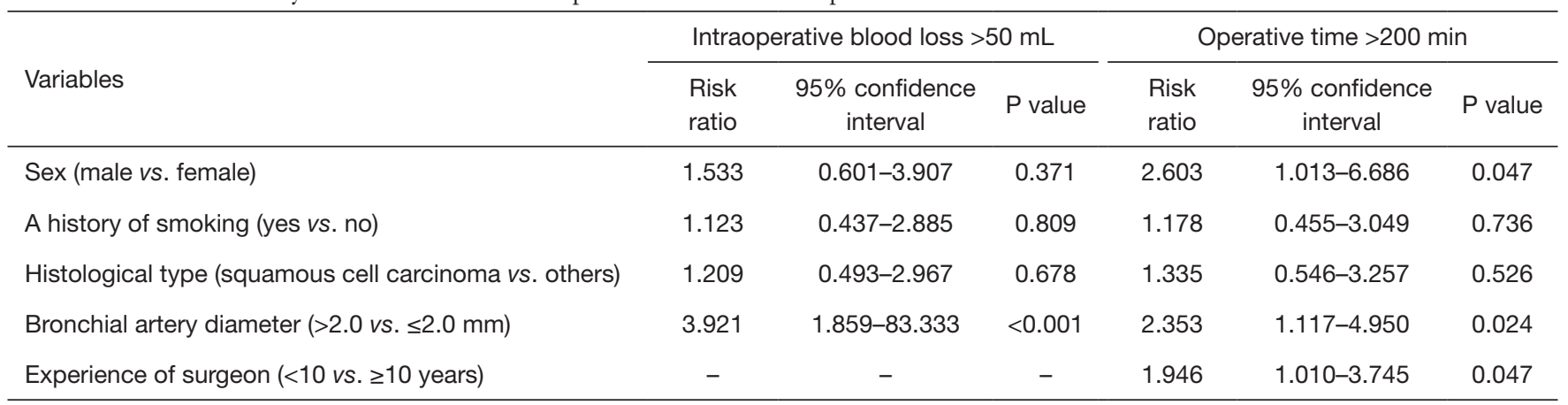

9 vs. 7 min; IQR, 8-13 vs. 6-9 min; $\mathrm{P}<0.0001)$.

\section{Discussion}

With advances in surgical techniques and devices, VATS has become a standard surgical procedure for lung cancer surgery (1). However, even thoracic surgeons with experience sometimes encounter unexpected intraoperative bleeding during VATS and, thus, the prolongation of operative times. The causes and incidence of intraoperative bleeding under 7 conditions are summarized by the International Interest Group on Bleeding during VATS Lung Surgery; bleeding from massive vessel injuries, bronchial arteries, vessel and bronchial stumps, lung parenchyma, lymph nodes, incisions, and the chest wall (13).

We herein focused on bronchial arteries because they supply blood to most intrathoracic tissues that may be incised or damaged during lobectomy and lymph node dissection. They provide a systemic blood supply to the trachea, bronchi, bronchial branches, esophagus, visceral pleura, vasa vasorum of the thoracic aorta, and pulmonary arteries as well as to the nerves, pulmonary veins, and lymph nodes in the thorax (12). In the present study, a bronchial artery diameter $>2.0 \mathrm{~mm}$ was the only risk factor for intraoperative bleeding in the multivariate analysis, even though many surgeons with different years of experience were involved in surgery. This is the first study to show that hypervascularized bronchial arteries significantly increased both intraoperative blood loss and the operative time.

Factors related to a bronchial artery diameter $>2.0 \mathrm{~mm}$ were being male, a history of smoking, the presence of interstitial lung disease, squamous cell carcinoma, and an advanced pathological stage. Bronchial arteries play an important role in diseases that affect the airways and lung parenchyma. One of the causes of bronchial artery dilatation is chronic or acute inflammation. The most common inflammatory lung and airway disorders associated with bronchial artery dilatation include tuberculosis and nontuberculous mycobacterial infections as well as chronic fungal infections $(10,14,15)$. Although a history of these infections was not examined in the present study, they may cause intrathoracic adhesions and lymph node swelling, resulting in increases in intraoperative bleeding and operative times. Chronic inflammatory changes caused by smoking or interstitial lung disease may also lead to bronchial artery dilatation. Lung cancer (frequently necrotic squamous cell cancer) is also a cause of bronchial artery dilatation $(10,16,17)$.

Intraoperative bleeding in cases with hypervascularized bronchial arteries has been observed during the following: (I) dissection of inflammatory intrathoracic adhesions; (II) dissection around hilar lymph nodes; (III) bleeding from the hilum or lung parenchyma due to lung congestion, and (IV) mediastinal lymph node dissection. Regarding bleeding from the hilum or lung parenchyma due to lung congestion, $\mathrm{Li}$ et al. previously reported that intraoperative blood loss was significantly less in the pulmonary vein sealing first group than in the pulmonary artery sealing first group (6). On the other hand, comparative studies by Sumitomo et al. (5) and Yellin et al. (7) did not show any significant differences in intraoperative blood loss between the two groups. Therefore, these findings and the present results suggest that intraoperative blood loss is affected by blood flow in the bronchial arteries rather than the sequence of vessel interruption.

Since patients with thick bronchial arteries are at risk of intraoperative bleeding during VATS lobectomy, risk management is required during surgery for these cases. Senior surgeons need to be aware that it may be difficult for an inexperienced resident to complete VATS lobectomy on a patient with highly vascularized bronchial arteries that 
Table 3 Factors correlating with bronchial artery dilation

\begin{tabular}{|c|c|c|c|c|c|}
\hline \multirow{2}{*}{ Variables } & \multicolumn{4}{|c|}{ Bronchial artery diameter } & \multirow{2}{*}{$P$ value } \\
\hline & $\mathrm{N}$ & $\%$ & $\mathrm{~N}$ & $\%$ & \\
\hline Age & & & & & 0.73 \\
\hline$<70$ years & 46 & 71.9 & 18 & 28.1 & \\
\hline Sex & & & & & $<0.001$ \\
\hline Male & 65 & 59.1 & 45 & 40.9 & \\
\hline Female & 58 & 89.2 & 7 & 20.8 & \\
\hline A history of smoking & & & & & $<0.001$ \\
\hline Tumor size & & & & & 0.66 \\
\hline$\leq 20 \mathrm{~mm}$ & 75 & 81.5 & 17 & 18.5 & \\
\hline$>20 \mathrm{~mm}$ & 48 & 57.8 & 35 & 42.2 & \\
\hline Tumor location & & & & & 0.06 \\
\hline Right upper & 38 & 59.4 & 26 & 40.6 & \\
\hline Right middle & 11 & 91.7 & 1 & 8.3 & \\
\hline Right lower & 24 & 66.7 & 12 & 33.3 & \\
\hline Left upper & 22 & 81.5 & 5 & 18.5 & \\
\hline Histological type & & & & & 0.049 \\
\hline Squamous cell carcinoma & 13 & 39.4 & 20 & 60.6 & \\
\hline Adenocarcinoma & 106 & 82.8 & 22 & 17.2 & \\
\hline Others & 4 & 28.6 & 10 & 71.4 & \\
\hline Pathological stage & & & & & 0.004 \\
\hline 0 & 4 & 100.0 & 0 & 0.0 & \\
\hline I & 107 & 74.8 & 36 & 25.2 & \\
\hline II & 10 & 43.5 & 13 & 56.5 & \\
\hline III & 2 & 40.0 & 3 & 60.0 & \\
\hline
\end{tabular}


Table 4 Operative and postoperative results correlating with bronchial artery dilation

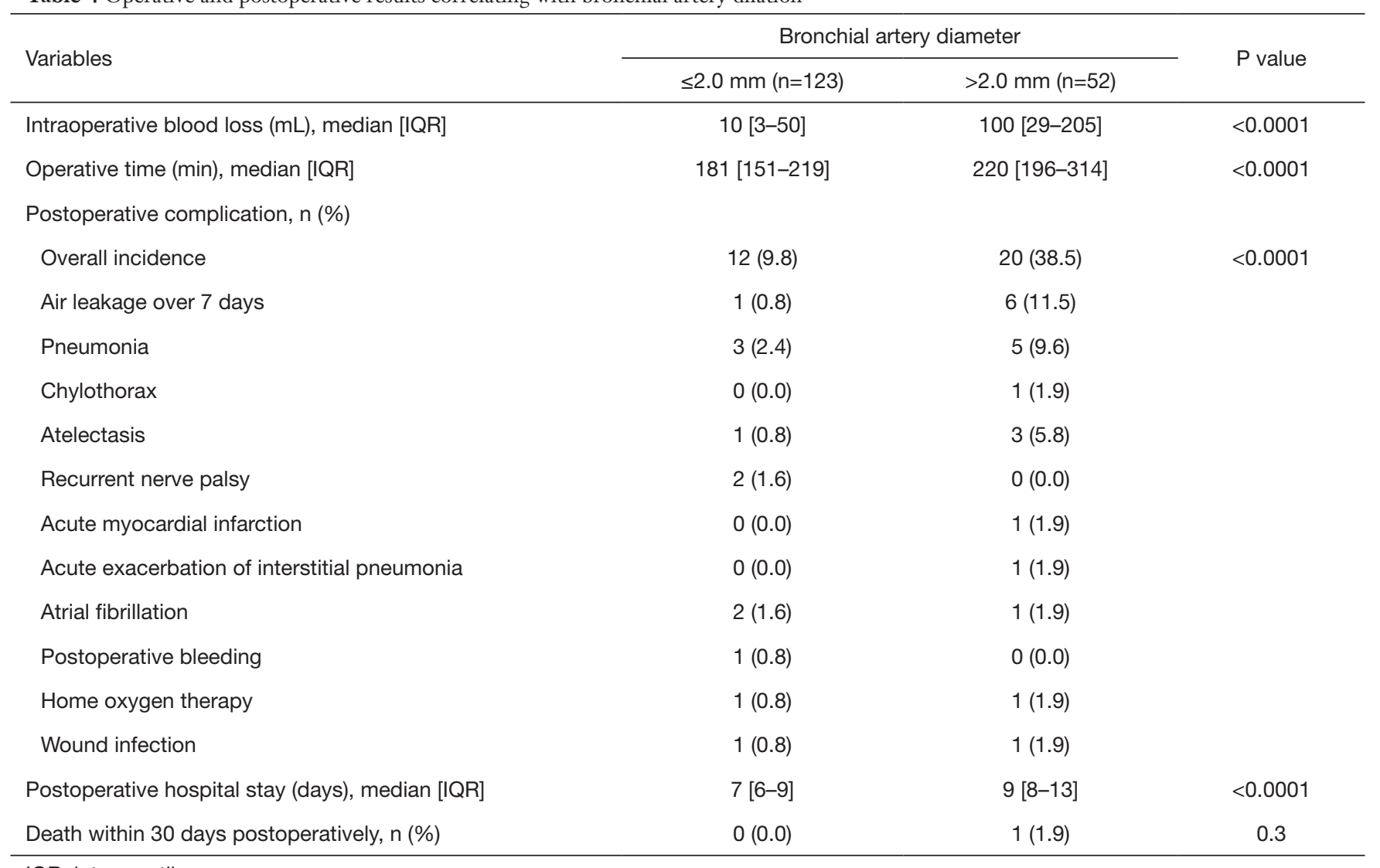

$I Q R$, interquartile range.

are detected by preoperative contrast-enhanced CT. The International Interest Group on Bleeding during VATS Lung Surgery states in their recommendations that the pre-emptive clipping of bronchial arteries before bronchial dissection or lymph node dissection may reduce the incidence of bleeding (13). Since bronchial arteries markedly vary in terms of origin, the parent artery, and course through the mediastinum $(8,9)$, they need to be carefully identified during surgery. Intraoperative observations using the indocyanine green fluorescent endoscopy system may facilitate the identification of bronchial arteries that run through the mediastinum and hilar and sealing before hilar dissection or lymph node dissection (18). The blockade of bronchial arteries first may reduce intraoperative bleeding and shorten the operative time. Further studies are warranted.

There are some limitations that need to be addressed. This was a retrospective study with a limited number of single-center cases. Furthermore, bronchial artery diameters were measured at the point arising from thoracic aorta. Right bronchial arteries often share their origin with an intercostal artery, a finding known as a common intercostalbronchial artery trunk $(8,9)$. Therefore, bronchial artery diameters may have been evaluated as being larger in cases with a tumor on the right side. Moreover, the present study did not consider ectopic arterial origins. Ectopic sites of origin include the subclavian artery, brachiocephalic trunk, thyrocervical trunk, internal mammary artery, and even a coronary artery $(9,19,20)$.

\section{Conclusions}

In cases with highly vascularized bronchial arteries, intraoperative bleeding increases during VATS lobectomy with systematic lymph node dissection, the operative time is prolonged, and postoperative complications increases. A bronchial artery diameter $>2.0 \mathrm{~mm}$ was identified as the independent risk factor for intraoperative bleeding in the multivariate analysis. Factors related to a bronchial artery diameter $>2.0 \mathrm{~mm}$ were being male, a history of smoking, the presence of interstitial lung disease, squamous cell 
carcinoma, and an advanced pathological stage.

\section{Acknowledgments}

Funding: None.

\section{Footnote}

Reporting Checklist: The authors have completed the STROBE reporting checklist. Available at https://dx.doi. org/10.21037/jtd-21-616

Data Sharing Statement: Available at https://dx.doi. org/10.21037/jtd-21-616

Peer Review File: Available at https://dx.doi.org/10.21037/ jtd-21-616

Conflicts of Interest: All authors have completed the ICMJE uniform disclosure form (available at https://dx.doi. org/10.21037/jtd-21-616). H Takizawa serves as an unpaid editorial board member of Fournal of Thoracic Disease from Feb 2021 to Jan 2023. The other authors have no conflicts of interest to declare.

Ethical Statement: The authors are accountable for all aspects of the work in ensuring that questions related to the accuracy or integrity of any part of the work are appropriately investigated and resolved. The study was approved by the Ethics Review Board of the Tokushima University Hospital (approval number 3362). The need for written informed consent was waived because of the retrospective study design. The study was conducted in accordance with the Declaration of Helsinki (as revised in 2013).

Open Access Statement: This is an Open Access article distributed in accordance with the Creative Commons Attribution-NonCommercial-NoDerivs 4.0 International License (CC BY-NC-ND 4.0), which permits the noncommercial replication and distribution of the article with the strict proviso that no changes or edits are made and the original work is properly cited (including links to both the formal publication through the relevant DOI and the license). See: https://creativecommons.org/licenses/by-nc-nd/4.0/.

\section{References}

1. Hartwig MG, D'Amico TA. Thoracoscopic lobectomy: the gold standard for early-stage lung cancer? Ann Thorac Surg 2010;89:S2098-101.

2. Lewis RJ, Caccavale RJ, Sisler GE, et al. One hundred consecutive patients undergoing video-assisted thoracic operations. Ann Thorac Surg 1992;54:421-6.

3. Committee for Scientific Affairs, The Japanese Association for Thoracic Surgery; Shimizu H, Okada M, et al.

Thoracic and cardiovascular surgeries in Japan during 2017 : Annual report by the Japanese Association for Thoracic Surgery. Gen Thorac Cardiovasc Surg 2020;68:414-49.

4. Yang CJ, Kumar A, Deng JZ, et al. A National Analysis of Short-term Outcomes and Long-term Survival Following Thoracoscopic Versus Open Lobectomy for Clinical Stage II Non-Small-Cell Lung Cancer. Ann Surg 2021;273:595-605.

5. Sumitomo R, Fukui T, Marumo S, et al. Effects of vessel interruption sequence during thoracoscopic lobectomy for non-small cell lung cancer. Gen Thorac Cardiovasc Surg 2018;66:464-70.

6. Li F, Jiang G, Chen Y, et al. Curative Effects of Different Sequences of Vessel Interruption During the Completely Thoracoscopic Lobectomy on Early Stage NonSmall Cell Lung Cancer. Ann Thorac Cardiovasc Surg 2015;21:536-43.

7. Yellin A, Sadetzki S, Simansky DA, et al. The sequence of vessel interruption during lobectomy: does it affect the amount of blood retained in the lobe? Eur J Cardiothorac Surg 2007;31:711-3.

8. Fei QL, Zhou YY, Yuan YX, et al. An applied anatomical study of bronchial artery. Surg Radiol Anat 2018;40:55-61.

9. Morita $\mathrm{Y}$, Takase K, Ichikawa H, et al. Bronchial artery anatomy: preoperative $3 \mathrm{D}$ simulation with multidetector CT. Radiology 2010;255:934-43.

10. Bruzzi JF, Rémy-Jardin M, Delhaye D, et al. Multidetector row CT of hemoptysis. Radiographics 2006;26:3-22.

11. McCullagh A, Rosenthal M, Wanner A, et al. The bronchial circulation--worth a closer look: a review of the relationship between the bronchial vasculature and airway inflammation. Pediatr Pulmonol 2010;45:1-13.

12. Pump KK. Distribution of bronchial arteries in the human lung. Chest 1972;62:447-51.

13. Liu L, Mei J, He J, et al. International expert consensus on the management of bleeding during VATS lung surgery. Ann Transl Med 2019;7:712.

14. Najarian KE, Morris CS. Arterial embolization in the chest. J Thorac Imaging 1998;13:93-104.

15. Marshall TJ, Jackson JE. Vascular intervention in the 
thorax: bronchial artery embolization for haemoptysis. Eur Radiol 1997;7:1221-7.

16. Panos RJ, Barr LF, Walsh TJ, et al. Factors associated with fatal hemoptysis in cancer patients. Chest 1988;94:1008-13.

17. Zhao LX, Gao Q, Liu YJ, et al. Study on 256-slice spiral CT bronchial artery imaging of common pathological types of central-type lung cancer. Eur Rev Med Pharmacol Sci 2016;20:3211-6.

Cite this article as: Takizawa $\mathrm{H}$, Miyamoto N, Sakamoto S, Takashima M, Matsumoto D, Kawakita N, Toba H, Kawakami Y, Yoshida M, Kondo K, Tangoku A. Hypervascularized bronchial arteries as a risk factor for intraoperative bleeding and prolonged surgery. J Thorac Dis 2021;13(8):4731-4741. doi: $10.21037 /$ jtd-21-616
18. Uramoto H, Motono N. ICG easily detects not only the segmental plane, but also the course and blood distribution of the bronchial artery"case report". Ann Med Surg (Lond) 2018;28:28-9.

19. Hartmann IJ, Remy-Jardin M, Menchini L, et al. Ectopic origin of bronchial arteries: assessment with multidetector helical CT angiography. Eur Radiol 2007;17:1943-53.

20. Loukas M, Hanna M, Chen J, et al. Extracardiac coronary arterial anastomoses. Clin Anat 2011;24:137-42. 